We conclude that the factors likely to predispose an individual towards an adverse response are (a) genetic, (b) underlying immunopathological conditions, $(c)$ frequency of exposure to a particular drug, and $(d)$ various combinations of these. Genetic factors include both IgE (atopy) and complement anomalies. Immunopathological conditions involving circulatory immune complexes, such as chronic infection, systemic lupus erythematosus, and rheumatoid arthritis, may "prime" complement systems, making them susceptible to activation by intravenous drugs. Adverse response can thus be attributed to a range of mechanisms and predisposing factors and no intravenous drug can be considered entirely safe.

JOHN WATKINS

A MILFORD WARD Neil Appleyard

Departments of Immunology and Aallamshire Hospital

Sheffield

Watkins, J, et al, British fournal of Anaesthesia, 1976, 48, 457. et al, British fournal of Anaesthesia, 1976 , fournal of Anaesthesia, 1976, 48, 1118 .

\section{Adverse reactions to Althesin}

SIR,-Drs J M Evans and J A M Keogh report (17 September, $p$ 735) a high incidence of adverse reactions after the administration of Althesin (alphadolone and alphaxolone in polyoxyethylated castor oil; Bayer) and suggest that the number is unacceptable. I am concerned that the authors should consider that such a retrospective study would be expected to reveal an accurate picture of the number of adverse reactions that occurred. An anaesthetist is unlikely to recall all the untoward events that occur at induction over 3-4 years and would tend to remember events associated with a new drug rather than the routine agent. I cannot remember a single serious adverse reaction associated with my administration of intravenous anaesthetic agents, including Althesin, over the past six years but do not accept that this is evidence that none occurred. Close observation at the time of induction will show that all intravenous induction agents are associated with adverse effects and these are likely to be higher when a new drug is introduced, especially if it is potent. Drs Evans and Keogh attempt to classify the type of reaction that occurred. I doubt that this is possible from the information available in a retrospective study. It is important to differentiate between anaphylactoid reactions and the pharmacological effects of overdose. This requires measurement.

Over recent years I have administered many Althesin anaesthetics, and in many cases cerebral function has been monitored. There is no doubt that patients react very differently to a standard weight-based dose, some developing signs of profound cortical depression. Adequate anaesthesia may be induced with only $1.5-2.5 \mathrm{ml}$ of Althesin yet anaesthetists, used to injecting $12-15 \mathrm{ml}$ of thiopentone, might not have adapted to the smaller volumes required when using Althesin.

Thiopentone was once described as an ideal method of euthanasia in war surgery. ${ }^{1}$ Its popularity could well have declined but for a further publication which suggested that it was the technique of administration and the dose of drug used that was at fault rather than the agent itself. ${ }^{2} 3$ We may now be seeing a similar situation with Althesin. Serious complications are likely to be reduced if induction agents are administered slowly in small doses, if blood pressure, heart rate, and even cerebral function are monitored during the induction period, and if an intravenous infusion is readily available. The incidence of anaphylactoid reactions will have to be worked out from the results of haematological and biochemical measurements. These may ultimately show that Althesin is particularly prone to induce adverse effects but I do not think one can accept the findings of a retrospective study. Meanwhile one can ponder on the mechanism of apnoea lasting 60 minutes after a single dose of Althesin. Someone could not possibly have given the wrong drug, could they?

T M SAVEGE Acting Director,
Anaesthetics Unit London Hospital Medical College,
London El

Halford, F J, Anesthesiology, 1943, 4, 67

Adams, R C, and Gray, H K, Anesthesiology, 1943, 4, Editorial, Anesthesiology, 1943, 4, 66

Seniority payments and service in HM Forces

SIR,-Dr W A Jerrett in his letter (17 September, $p$ 774) draws attention to a gross injustice in that service in the armed Forces does not count towards seniority in general practice, except as a "senior" medical officer. The Ministry of Defence should now warn all serving and potential medical officers that their five years of service, even if spent in general practice, will not count towards seniority payments. Perhaps they could include this information in the recruiting information they send to medical students who apply to join the armed Forces.

Pont ypridd,
Mid Glamorgan

C B A LlOYD-WILliaMS

\section{General practitioner prescribing costs}

SIR,-Dr R T A Scott's letters (30 July, p 319, 10 September, $p$ 708) raised two very different questions. His suggestion in the later letter of a limited list of drugs for free or subsidised use is an attractive one and makes the prescribers' decisions much easier. Dr Scott's first question about the teaching of future general practitioners is even more pertinent now that, according to the DHSS's annual report of 1976, English general practitioners' prescribing costs averaged more than $£ 22000$ each. Classes on prescribing costs were begun in the Wessex day-release course in 1974, when a colleague presented the results of a prescription pricing inquiry into his practice. This was followed by exercises in practical prescribing and questions on attitudes to prescribing. These clearly confirmed that "the question of cost plays no part in choosing drug treatments" was a view prevalent among trainees in 1974-5. Since then further classes have been held and the discussion of cost is now seen by trainees as a factor of importance in choosing treatment, especially where doctors try to agree on joint policies. Even so, we recognise that economy in GP prescribing costs can play only a limited part in keeping down the cost of the health service. A $12 \%$ reduction in prescribing (requiring an average of 150 fewer prescriptions per doctor per month) would result in less than $1 \%$ change in the total cost of the NHS.

P P CARTER

Southampton,

Hants

\section{Costs of prescribing}

SIR,-_Professor O L Wade recently delivered a lecture to the British Association for the Advancement of Science on "The problems (of the cost) of Drug Prescribing in the National Health Service." In it he evaluates most helpfully many of the problems in financing medication. ${ }^{1}$ However, towards the end of the paper he suggests that monetary incentives could be used to curb wasteful prescribing in general practice. "Each doctor might be given a 'drug allowance' of $£ 400$ to $£ 500$ per 100 patients on his list to meet the cost of his prescribing. If he prescribes in excess of this, other than in exceptional circumstances, the excess would be met from his practice; if he prescribes within his budget the saving would accrue to his practice to be available for other services."

Unfortunately, one of the snags of the pool as a method of payment is that no one group of doctors can be given additional sums of money without this being subtracted at national level from the remuneration of all remaining practitioners. Thus, what sets out to be an inducement turns out to be a penalty, particularly on the conscientious doctor as well as to the body of general practitioners as a whole. I remember the days when I used to dispense for my own rural practice and chose the capitation system (now 52p per patient). I am well aware of the substantial savings available to be made from prescribing what one dispenses-but in urban practice, with independent chemists, the problem is more complex. The outcome of this system of pseudo inducements would lead to deterioration of health care.

At present there are only a few drugs, borderline substances, for which the GP may be asked to undertake the cost of prescribing himself. Legislation of this type would convert all drugs to this class in that the practitioner would be at risk to cover the cost of his patients' needs should they rise above an arbitrary limit. With inflation raising the price of drugs, increased reluctance of hospitals to prescribe what they recommend, and inflation massively eroding the doctors' income, that proportion of the cost of the doctors' drug bill which politicians would allow to fall as a debt on our pockets would be bound to increase to save the public purse.

Doctors with a large turnover of mobile patients, those looking after a preponderance of the elderly, those caring for homes for the elderly, subnormal, or mentally handicapped -all these doctors would find themselves penalised in so far as their drug expenses would be disproportionately high for having accepted responsibility for more difficult patients. What doctor would involve himself in screening his practice if the cost of treating identified cases might fall on his own pocket? What chance have ill patients of being accepted by a new doctor if he can see that they are persons liable to require expensive medication? What GP can afford to look after a child who, happening to have phenylketonuria, has come 